\title{
Energy intensity and environmental impact metrics of the back-end separation of ethylene plant by thermodynamic analysis
}

\author{
Mahdi Alhajji ${ }^{1} \cdot$ Yaşar Demirel $^{1}$
}

Received: 2 June 2015/Accepted: 22 September 2015/Published online: 9 November 2015

(C) The Author(s) 2015. This article is published with open access at Springerlink.com

\begin{abstract}
This study presents metrics of energy intensity and environmental impact of the back-end separation of ethylene plant consisting three interacting distillation columns by thermodynamic analysis. The objective is to explore the scope of reducing the energy for utilities and $\mathrm{CO}_{2}$ emissions. Thermodynamic analysis is carried out using the column targeting tool (CTT) to address the sustainability metrics of 'Energy Intensity.' CTT is based on the 'Practical Near-Minimum Thermodynamic Condition' representing a close to practical reversible column operation. Environmental impact metrics are estimated from the carbon tracking options. The carbon tracking are estimated by the $\mathrm{CO}_{2}$ emission data source of US-EPA-Rule-E9-5711 using natural gas as the primary fuel. The results show that the total reductions in exergy loss and the total hot and cold utility are around 44 and $10 \%$, respectively; the total reductions in carbon dioxide are around $14 \%$. These improvements lead to considerable reductions in the operating costs. Thermodynamic analysis helps estimating and improving the energy and environmental sustainability metrics and hence can lead to a more sustainable separation by distillation columns.
\end{abstract}

Keywords Ethylene plant - Distillation column · Column targeting tool - Exergy loss profiles · Energy intensity . Environmental impact metrics

Electronic supplementary material The online version of this article (doi:10.1007/s40095-015-0194-9) contains supplementary material, which is available to authorized users.

Yaşar Demirel

ydemirel2@unl.edu

1 Department of Chemical and Biomolecular Engineering, University of Nebraska Lincoln, Lincoln, NE 68588, USA

\section{Introduction}

Distillation-based separations consume about $40 \%$ of the total energy used in petrochemical and chemical process industries in North America [1,2]. The relatively high purity recovery and low relative volatility require toll distillation columns with very high installation and operating costs in ethylene plants [3]. Therefore, the olefin/paraffin separation process of ethylene, propylene and other high-volume olefin petrochemicals is highly energy-intensive, and hence impacts environment. Cryogenic distillation is the commercially viable separation; however, it consumes over 20 Gigajoules of energy for every ton of ethylene produced. This energy consumption is associated with significant greenhouse gas emission and depletion of non-renewable energy resources. Consequently, there is a strong economic incentive to reduce the costs through improved process designs for the back-end separation of ethylene by distillation [3, 4].

A typical distillation column resembles a heat engine [2] delivering separation work by using heat at a high temperature in the reboiler and discharging most of it to the environment at a lower temperature in the condenser $[5,6]$. One of the thermodynamic methodologies to assess the distillation column operation is the column targeting tool (CTT), which is based on the practical near-minimum thermodynamic condition (PNMTC) approximation representing a practical and close to reversible operation [7, 8]. CTT exploits the capabilities for thermal and hydraulic analyses of distillation columns $[4,7]$ to identify the targets for possible column retrofits for (1) feed stage location, (2) reflux ratio, (3) feed conditioning, and (4) side condensing and/or reboiling to reduce the cost of utilities and improve the overall energy efficiency [9-11]. The 'carbon tracking' options of the Aspen Plus can help quantify the reduction in $\mathrm{CO}_{2}$ emission in a simulation environment [8]. 
Sustainability has environmental, economic, and social dimensions [12, 13] and requires the responsible use of energy resources and reduction in $\mathrm{CO}_{2}$ emission. The three intersecting dimensions illustrate the 3D-sustainability metrics that include nonrenewable energy use, toxic, and pollutant emissions per unit product $[14,15]$. If nonrenewable, energy usage affects environment adversely through the emission of pollutants such as $\mathrm{CO}_{2}$. Therefore, a comparative assessment with the sustainability metrics may prove useful in identifying the scope for retrofits for possible reductions of the waste energy and emission of $\mathrm{CO}_{2}$ for the three interacting distillation columns of a typical ethylene plant. The energy metrics are estimated from the CTT, while the carbon emission from the data source of US-EPA-Rule-E9-5711 using the fuel source of natural gas.

\section{Ethylene plant}

Ethylene is produced by steam cracking in which light hydrocarbons are heated to $750-950{ }^{\circ} \mathrm{C}$, inducing numerous reactions. Ethylene is separated from the resulting complex mixture by repeated compression and distillation processes. The separation of ethylene from ethane by distillation is normally the final step in the production of ethylene. The separation of ethylene is expensive because (1) the required purity of ethylene usually exceeds $99.9 \%$ and (2) the relative volatility of ethylene to ethane is moderately small ranging from about 1.13 for high-pressure mixtures rich in ethylene to 2.34 for low-pressure mixtures rich in ethane. Ethylene fractionation separates ethylene as a highly pure overhead product, $99.9 \mathrm{wt} \%$, free of olefins, acetylenes, dienes, and water. Ethylene production is close to the historic mid-range of 145 million $\mathrm{lb} /$ day in the U. S. States. Global production of ethylene was about 141 million $\mathrm{mt}$ in 2011 [3]. Approximately $90 \%$ of ethylene is used to produce ethylene oxide, ethylene dichloride, ethyl benzene, and polyethylene.

Figure 1 shows the back-end separation of a conventional ethylene plant. As shown in Fig. 1, stream 12 has a flow of $20.39 \mathrm{~kg} / \mathrm{s}$, at $16^{\circ} \mathrm{C}$ and $39 \mathrm{bar}$, consists of $5.83 \mathrm{~kg} / \mathrm{s}$ of ethane, $10.98 \mathrm{~kg} / \mathrm{s}$ of ethylene, $1.96 \mathrm{~kg} / \mathrm{s}$ of hydrogen, $1.12 \mathrm{~kg} / \mathrm{s}$ of methane, $0.003 \mathrm{~kg} / \mathrm{s}$ of acetylene, $0.342 \mathrm{~kg} / \mathrm{s}$ of propylene, $0.111 \mathrm{~kg} / \mathrm{s}$ of propane, $0.012 \mathrm{~kg} / \mathrm{s}$ of butadiene, $0.007 \mathrm{~kg} / \mathrm{s}$ of butene, $0.011 \mathrm{~kg} / \mathrm{s}$ of butane, and $0.003 \mathrm{~kg} / \mathrm{s}$ of benzene. The feed enters a splitter S2. The separated streams pass through reactors and flash separators till they reach the separation section containing the three RadFrac columns. The streams pass through the columns to produce ethylene as the distillate from column 3 and ethane as the bottom product which is recycled to C2REC reactor. Propylene is the bottom stream of column 2. The reactor between column 2 and column 3 converts the small amount of acetylene $(0.022 \mathrm{ton} / \mathrm{h})$ to ethylene, which is converted into ethane completely using $1.36 \mathrm{kmol}$ hydrogen at $-37.78{ }^{\circ} \mathrm{C}$ and 21.1 bar. The reactor receives the 137.23 ton/h gas distillate at $-13.7^{\circ} \mathrm{C}$ and $23.9 \mathrm{bar}$ from column 2. The outlet of the reactor is 137.23 ton $/ \mathrm{h}$ consisting of $41.2 \mathrm{wt} \%$ of ethane and $58.6 \mathrm{wt} \%$ of ethylene.

This study focuses on the separation section having three distillation columns as shown in Fig. 1. Column 1 has three feeds and the overhead contains the hydrogen and methane which are recycled, while the bottom flow contains the mixture of ethane, ethylene, propylene, butadiene, butane, butane, and benzene which are separated in column 2 to a bottom flow containing propylene, propane, butadiene, butane, and benzene. Ethane and ethylene in the

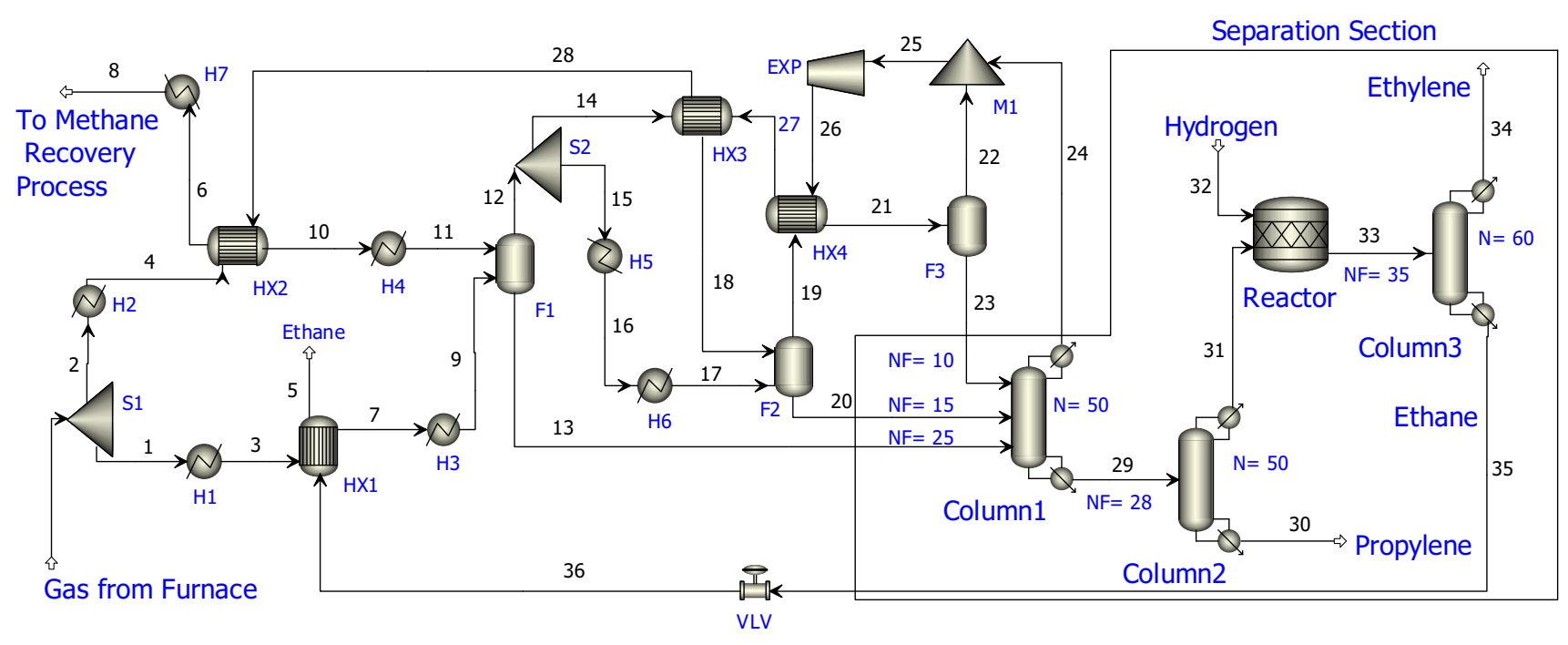

Fig. 1 Process flow diagram of ethylene plant with back-end separation 
Table 1 Column base case configurations: $N$ number of total stages; $N F 1, N F 2$, and $N F 3$ are the feed stages; $R R$ is the molar reflux ratio; $F$ is the total mass flow rate; $P$ is the column pressure; $T F 1, T F 2$, and $T F 3$ are the feed temperatures, and $P F 1$, $P F 2$, and $P F 3$ are the feed pressures [8]

\begin{tabular}{|c|c|c|c|}
\hline Configuration & Column 1 & Column 2 & Column 3 \\
\hline$N$ & 50 & 50 & 60 \\
\hline$N F$ & $\begin{array}{l}N F 1=25 \\
N F 2=15 \\
N F 3=10\end{array}$ & 28 & 35 \\
\hline Mole RR & 0.65 & 0.53 & 4.75 \\
\hline$F(\mathrm{~kg} / \mathrm{s})$ & $\begin{array}{l}F 1=27.03 \\
F 2=16.62 \\
F 3=1.04\end{array}$ & 43.85 & 38.12 \\
\hline$P(\mathrm{kPa})$ & 3447.38 & 2344.22 & 1654.74 \\
\hline$T F\left({ }^{\circ} \mathrm{C}\right)$ & $\begin{array}{l}T F 1=-37 \\
T F 2=-98 \\
T F 3=-129\end{array}$ & 5.50 & -24.60 \\
\hline$P F(\mathrm{kPa})$ & $\begin{array}{l}P F 1=3688.71 \\
P F 2=3447.38 \\
P F 3=3447.38\end{array}$ & 3447.38 & 1723.69 \\
\hline Condenser duty (MW) & -0.29 & -6.38 & -37.81 \\
\hline Condenser temp. $\left({ }^{\circ} \mathrm{C}\right)$ & -99.58 & -13.68 & -35.92 \\
\hline Reflux rate $(\mathrm{kg} / \mathrm{s})$ & 0.59 & 22.09 & 100.87 \\
\hline Distillate rate $(\mathrm{kg} / \mathrm{s})$ & 0.83 & 38.12 & 22.33 \\
\hline Reboiler duty (MW) & 9.33 & 16.26 & 32.20 \\
\hline Reboiler temp. $\left({ }^{\circ} \mathrm{C}\right)$ & 5.53 & 74.41 & -15.00 \\
\hline Boilup rate $(\mathrm{kg} / \mathrm{s})$ & 36.23 & 6.76 & 82.71 \\
\hline Bottoms rate $(\mathrm{kg} / \mathrm{s})$ & 43.85 & 5.73 & 15.78 \\
\hline
\end{tabular}

presence of hydrogen go to the overhead and finally become the feed to column 3 where ethylene is the overhead product, while the ethane in the bottom is recycled. Table 1 shows the base configurations of the three columns. The Soave-Redlich-Kwong equation of state is used in the simulation of the plant.

\section{Materials and methods}

\section{Sustainability}

The Center for Waste Reduction Technologies (CWRT) of the American Institute of Chemical Engineers (AIChE) and the Institution of Chemical Engineers (IChemE) proposed a set of sustainability metrics applicable to a specific process [12-15, 22, 23]:

- Material intensity (nonrenewable resources of raw materials, solvents/unit mass of product(s))

- Energy intensity (nonrenewable energy/unit mass of $\operatorname{product}(\mathrm{s}))$

- Potential environmental impact (pollutants and emissions/unit mass of product(s))

- Potential chemical risk (toxic emissions/unit mass of $\operatorname{product}(\mathrm{s}))$

\section{Carbon tracking}

The carbon tracking option may be based on the $\mathrm{CO}_{2}$ emission factor data source of US-EPA-Rule-E9-5711 (used in this study) or EU-2007/589/EC as well as on a selected fuel source, such as natural gas, biogas, petroleum, or coal as summarized in Table 2 .

For distillation column operations, this study uses a comparative assessment with the following sustainability metrics:

- 'Energy intensity' as nonrenewable energy/unit mass of product(s) by using the CTT.

- 'Potential environmental impact' as emissions and cost/ unit mass of product(s) by using the 'carbon tracking' options.

\section{Column targeting tool}

The column targeting tool is a retrofit tool for lowering cost of operation through modified operating conditions and providing insight into understanding tray/packing capacity limitations. The CTT is based on the practical near-minimum thermodynamic condition representing a close to practical reversible column operation [20]. The CTT 
Table 2 Carbon dioxide emission rates for various $\mathrm{CO}_{2}$ emission factor data sources and fuel sources [8]

\begin{tabular}{lll}
\hline Fuel sources & \multicolumn{2}{l}{$\mathrm{CO}_{2}$ emission factor data sources, lb/MMBtu } \\
\cline { 2 - 3 } & US-EPA-Rule-E9-5711 & EU-2007/589/EC \\
\hline Natural gas & 130.00 & 130.49 \\
Petroleum-coke & 250.21 & 226.78 \\
Coal bituminous & 229.02 & 219.81 \\
Coal anthracite & 253.88 & 228.41 \\
Crude oil & 182.66 & 170.49 \\
Bio gas & 127.67 & 0 \\
\hline
\end{tabular}

performs (1) thermal, (2) exergy, and (3) hydraulic analyses capabilities that can help identify the targets for appropriate column modifications in order to (1) reduce utilities cost, (2) improve energy efficiency, (3) reduce capital cost by improving thermodynamic driving forces, and (4) facilitate column debottlenecking [4, 10-17, 19, 21]. These capabilities within the CTT are summarized below.

\section{Thermal analysis}

Thermal analysis capability distributes reboiling and condensing loads over the temperature range of operation to help identify design targets for improvements in energy consumption and efficiency $[1,2,5]$. In order to achieve this, the thermal analysis produces 'Column Grand Composite Curves' (CGCC) and 'Exergy Loss Profiles.' The user makes changes to column configurations and specifications until CGCCs and exergy profiles display closer actual and ideal operations $[14,16]$. The CGCCs are displayed as the stage-enthalpy (Stage- $H$ ) or temperatureenthalpy $(T-H)$. They represent the theoretical minimum heating and cooling requirements in the temperature range of separation. This approximation takes into account the inefficiencies introduced through column design and operation, such as mixing, pressure drops, multiple sideproducts, and side strippers. Using CGCC is significant because (1) it is a graphical tool to assess the current energy use and flow conditions of distillation operations, (2) it is based on the complex and rigorous stage-by-stage calculations, and (3) it can lead to the qualitative and quantitative guidance $[4,13,15,16]$ in identifying the targets for potential column modifications for the following:

1. Feed stage location (appropriate placement),

2. Reflux ratio modification (reflux ratio versus number of stages),

3. Feed conditioning (heating or cooling),

4. Side condensing or reboiling (adding side heater and/or cooler).
For estimation the enthalpy deficits, the equations for equilibrium and operating lines are solved simultaneously at each stage for specified light key and heavy key components. Using the equilibrium compositions of light $L$ and heavy $H$ key components, the enthalpies for the minimum vapor and liquid flows are obtained and used in the enthalpy balances at each stage to determine the net enthalpy deficits $[10,12,19]$.

$H_{\text {def }}=H_{\mathrm{Lmin}}-H_{\mathrm{V} \min }+H_{D} \quad$ (before the feed stage $)$

$H_{\text {def }}=H_{\mathrm{Lmin}}-H_{\mathrm{V} \min }+H_{D}-H_{\text {feed }} \quad$ (after the feed stage)

After adding the individual stage enthalpy deficits to the condenser duty, the enthalpy values are cascaded and plotted in the CGCC. This is called the top-down calculation procedure [10]. At the feed stage, mass and energy balances differ from an internal stage and the enthalpy deficit becomes

$$
\begin{aligned}
H_{\text {def }, \mathrm{F}}= & Q_{C}+D\left[H_{D}+H_{L}\left(x_{D}-y_{F}^{*}\right) /\left(y_{F}^{*}-x_{F}^{*}\right)\right. \\
& \left.-H_{V}\left(x_{D}-x_{F}^{*}\right) /\left(y_{F}^{*}-x_{F}^{*}\right)\right]
\end{aligned}
$$

The values of $y_{F}^{*}$ and $x_{F}^{*}$ may be obtained from an adiabatic flash for a single-phase feed, or from the constant relative volatility estimated with the converged compositions at the feed stage and feed quality. This procedure can be reformulated for multiple feeds and side products as well as different choices of the key components. In a CGCC, a pinch point near the feed stage occurs for nearly binary ideal mixtures. However, for nonideal multicomponent systems multiple pinches may exist in rectifying and stripping sections.

\section{Exergy analysis}

Physical exergy (Ex) is the maximum amount of work that may be performed theoretically by bringing a resource into equilibrium with its surrounding through a reversible process:

$\mathrm{Ex}=\Delta H-T_{o} \Delta S$,

where $H$ and $S$ are the enthalpy and entropy, respectively, and $T_{o}$ is the reference temperature, which is usually assumed as the environmental temperature of $298.15 \mathrm{~K}$. Exergy balance for a steady state system is

$$
\begin{aligned}
& \sum_{\substack{\text { into } \\
\text { system }}}\left[\dot{n} \mathrm{Ex}+\dot{Q}\left(1-\frac{T_{o}}{T_{s}}\right)+\dot{W}_{s}\right] \\
& -\sum_{\substack{\text { out of } \\
\text { system }}}\left[\dot{n} \mathrm{Ex}+\dot{Q}\left(1-\frac{T_{o}}{T_{s}}\right)+\dot{W}_{s}\right]=\dot{\mathrm{Ex}}_{\mathrm{loss}},
\end{aligned}
$$

where $\dot{W}_{s}$ is the shaft work. In general, the exergy loss profiles can be used to examine the degradation of 
accessible work due to (1) momentum loss (pressure driving force), (2) thermal loss (temperature driving force), and (3) chemical potential loss (mass transfer driving force) $[1,8,17,20]$.

The exergy profiles are plotted as state-exergy loss or temperature-exergy loss. A part of accessible work potential is always lost in any real process. Exergy losses (destructions) represent inefficient use of available energy due to irreversibility and should be reduced by suitable modifications $[12,16]$. As the exergy loss increases, the net heat duty has to increase to enable the column to achieve its required separation task. Consequently, smaller exergy loss means less waste energy.

\section{Thermodynamic efficiency}

Thermal efficiency can be defined as a thermal performance of an operation or a process. Thermodynamic efficiency is estimated depending on the sign of the main goal: Eq. (6) for the negative main goal and Eq. (7) for the positive one

$\eta_{(-) \mathrm{Ex}_{\min }}=\frac{\mathrm{Ex}_{\min }}{\mathrm{Ex}_{\min }-\mathrm{Ex}_{\text {loss }}}$

$\eta_{(+) \mathrm{Ex}_{\min }}=\frac{\mathrm{Ex}_{\min }}{\mathrm{Ex}_{\min }+\mathrm{Ex}_{\text {loss }}}$

The main goal is the minimum exergy loss in accomplishing that goal [24]. Minimum exergy determined by calculating the difference between exergies of products and the feed streams

$\mathrm{Ex}_{\min }=\sum_{\text {out }} \dot{n} \mathrm{Ex}-\sum_{\text {in }} \dot{n} \mathrm{Ex}$,

where $\dot{n}$ is the molar flow rate.

\section{Hydraulic analysis}

The hydraulics analysis produces the stage profiles for (1) thermodynamic ideal minimum flow, (2) hydraulic maximum flow, and (3) actual flow that help understand how the vapor and liquid flow rates in a column compare with the minimum (corresponding to the PNMTC) and maximum (corresponding to flooding) limits. Therefore, it can be used to identify and eliminate column bottlenecks [9-11]. Tray or packing rating for the entire column is necessary to activate the hydraulic analysis. In addition, allowable flooding factors (as fraction of total flooding) for flooding limit calculations can be specified. Hydraulic analysis helps identify the allowable limit for vapor flooding on the Tray RatinglDesign/Pdrop or Pack Rating|Design/Pdrop options. The default values are $85 \%$ for the vapor flooding limit and $50 \%$ for the liquid flooding limit. The liquid flooding limit specification is available only if the downcomer geometry is specified. The allowable limit for liquid flooding (due to downcomer backup) can be specified on the Tray RatinglDowncomers block. For packed and tray columns, jet flooding controls the calculation of vapor flooding limits. For tray columns, parameters such as downcomer backup control the liquid flooding limits.

\section{Results and discussion}

Figure 2 displays the back-end separation of the ethylene plant considered in this study. Table 1 presents the basecase configurations for all the columns, which operate with large number of stages under high pressure, large reboiler duties, and large boilup rates. Column 3, especially, requires very large hot and cold utilities. The column
Fig. 2 Section of ethylene plant back-end separation; $N$ : number of total stages; $N F$ : feed plate location

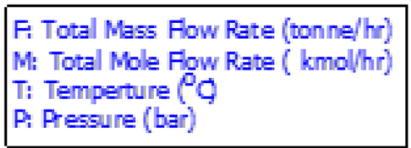

P. Pregoure (bar)

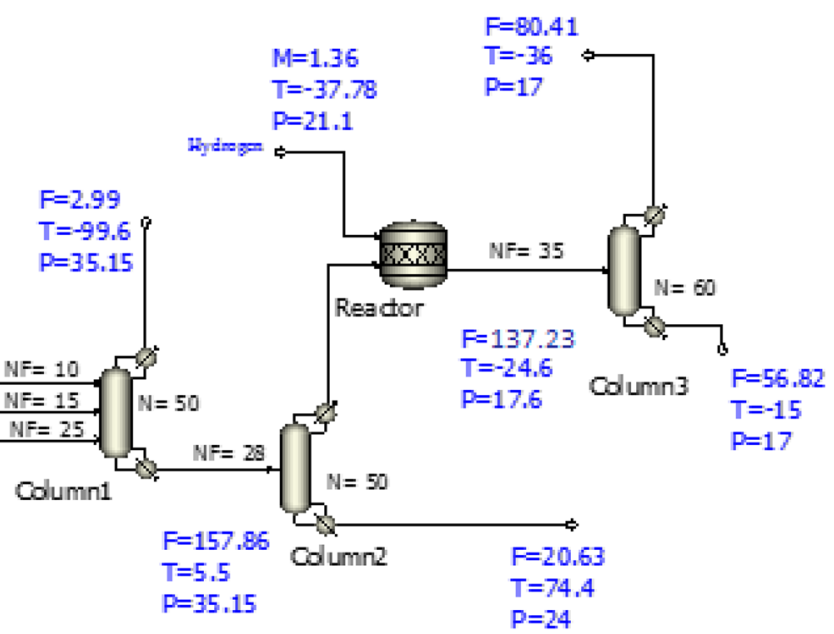


Fig. 3 Base case operation for column 1 with: $N=50$;

$N F 1=25, N F 2=15$,

$N F 3=10 ; R R=0.65 ; N$ : number of total stages; $N F 1$, $N F 2, N F 3$ are the feed stages, and $R R$ is the reflux ratio. a CGCC (stage- $H$ ), b exergy loss profiles, and $\mathbf{c}$ hydraulic analysis (a)

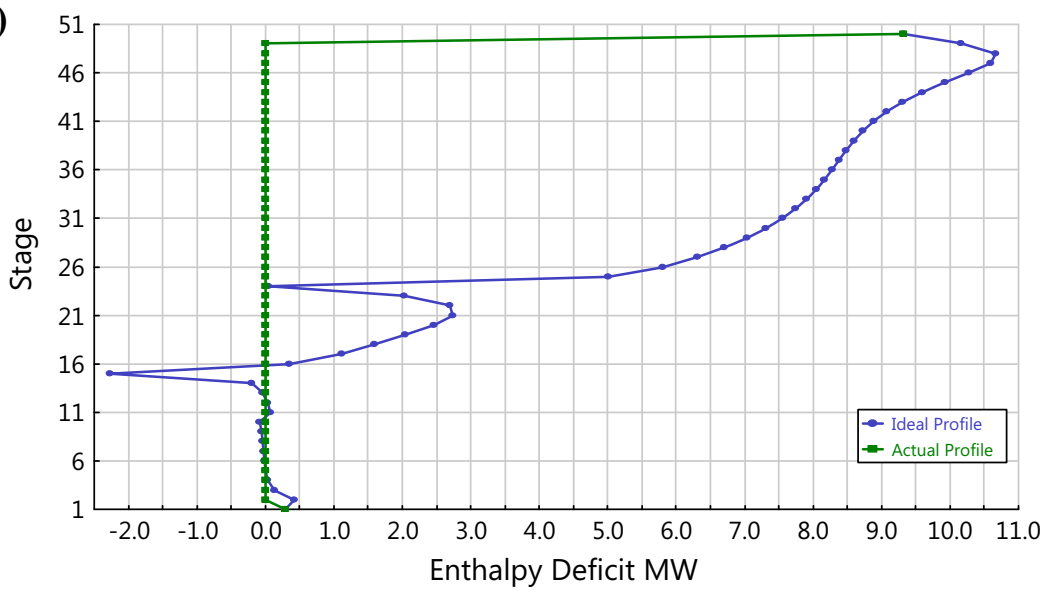

(b)
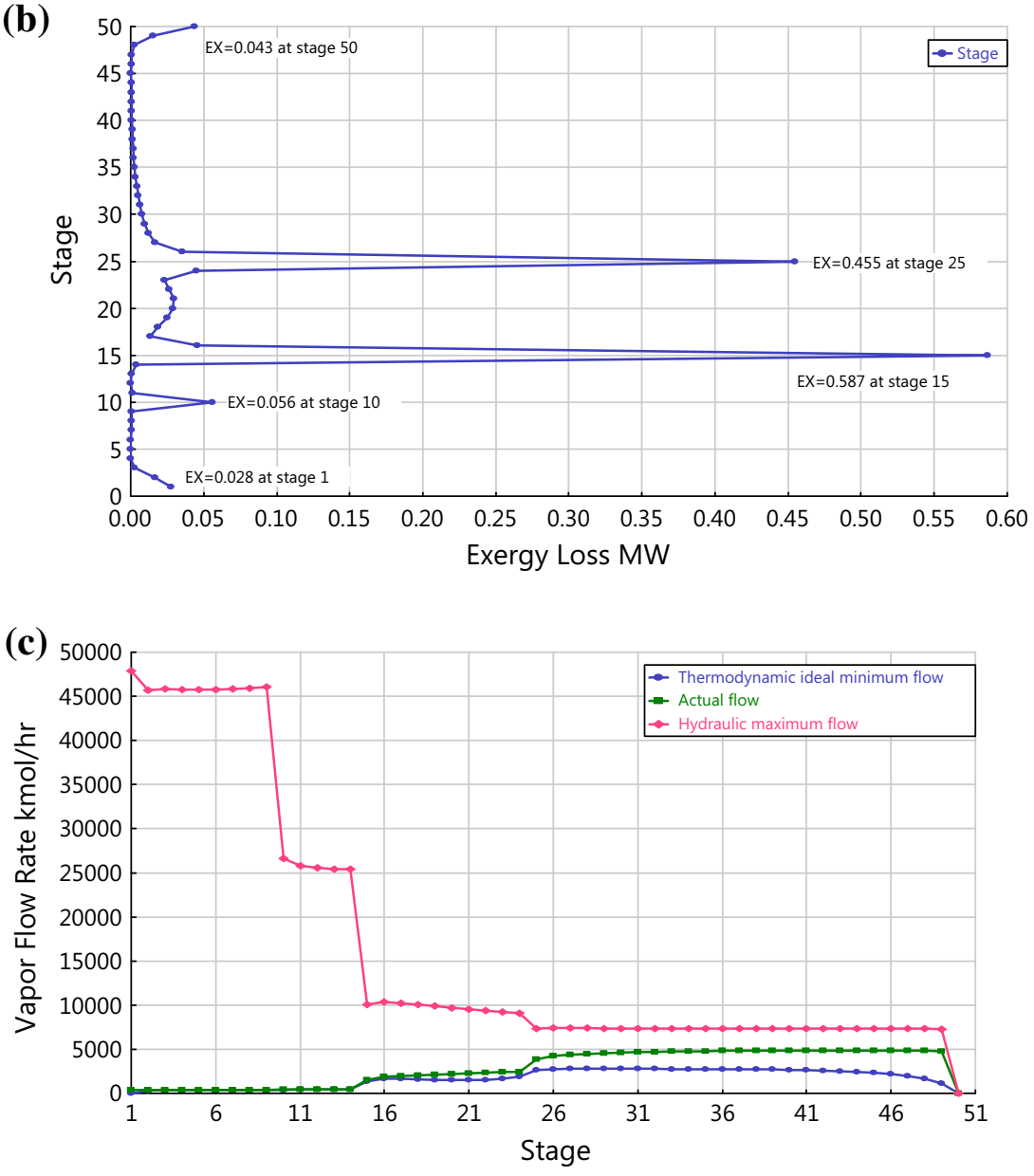

targeting tool with activated carbon tracking is used to reduce the duties for condensing and reboiling, stage exergy losses, as well as the carbon dioxide emissions due to the utilities for all the columns. The modified case operations with the determined scope of retrofits are compared with the base case operations to analyze and assess the impact of retrofits in the selected sustainability metrics.

\section{Feed location modification}

In the analysis, the condenser and reboiler are defined to be the first and last stages, respectively.

- If a feed is introduced too high up in the column, a sharp enthalpy change occurs on the condenser side on the stage- $H$ CGCC plot; the feed stage should be moved down toward the reboiler. 
Fig. 4 Modified case operation for Column 1 with $N=55$; $N F 1=25, N F 2=15$, $N F 3=10 \rightarrow 11 ; R R=0.38$; $T F 1=-37{ }^{\circ} \mathrm{C} \rightarrow-30{ }^{\circ} \mathrm{C} ; N$, number of total stages; $N F 1$, $N F 2$, and $N F 3$ are the feed stages, and $R R$ is the reflux ratio. a CGCC (stage- $H$ ), and b exergy loss profiles
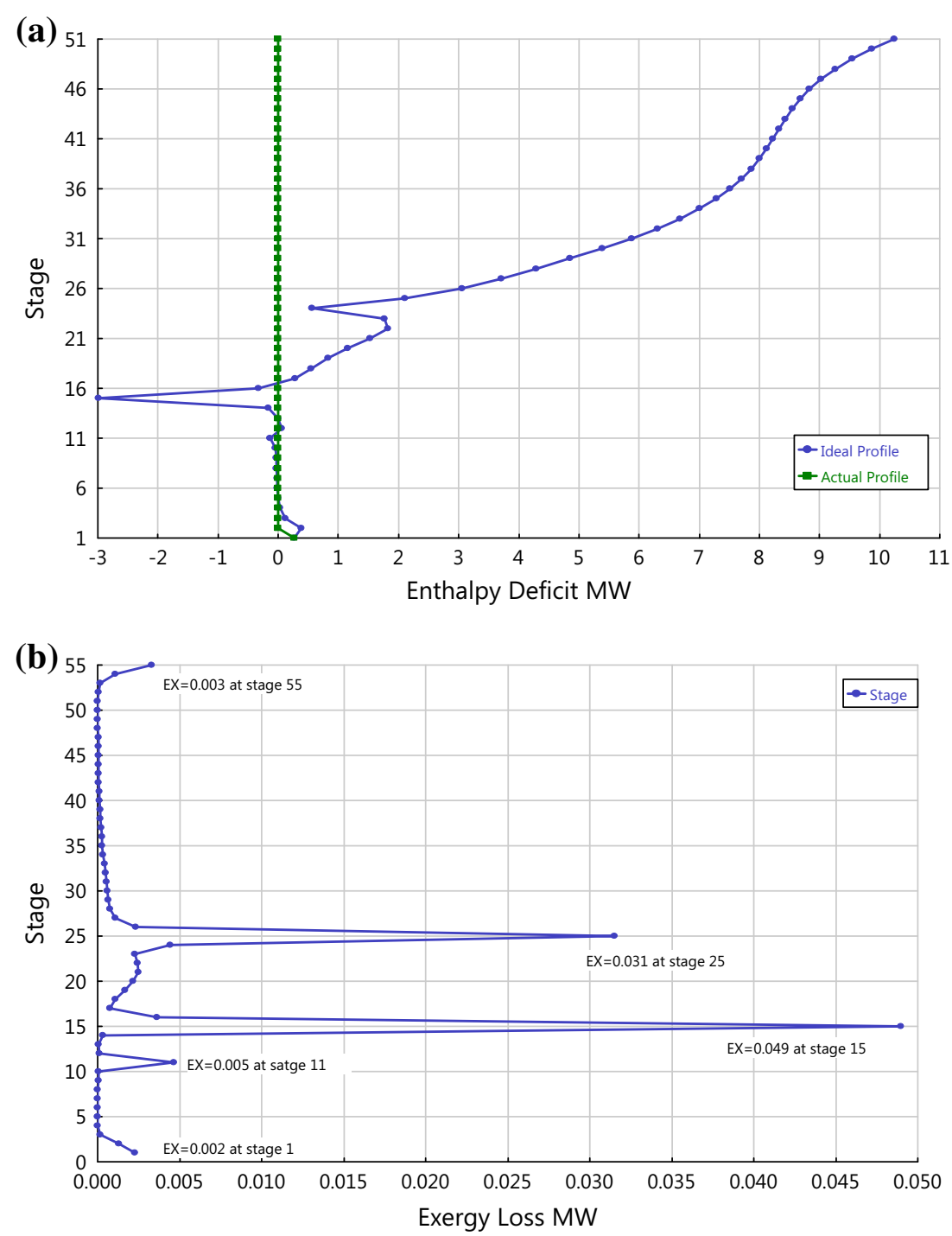

- If a feed is introduced too low in the column, a sharp enthalpy change occurs on the reboiler side on the stage- $H$ CGCC; the feed stage should be moved up toward the condenser [1, 10].

When the feed locations are appropriate, these distortions are less sharp and this may lead to reduced reboiler and condenser duties as well as exergy losses. However, in this case the modification of the feed plate location shows a negligible, or a very small reduction in column 1 duties and $\mathrm{CO}_{2}$ emission but not the exergy loss, while no noticed reduction in column 2 . On the other hand, column 3 modification shows reductions in duties and $\mathrm{CO}_{2}$ emission. This will be discussed more in the scope of reflux ratio modification, which requires changing the number of total stages and the feed plate locations.

\section{Feed conditioning modification}

Feed conditioning is necessary when sharp enthalpy change in reboiler or condenser is noticed on the stage- $H$ CGCC plot:

- If a feed is excessively sub-cooled, the stage- $H$ plots show a sharp enthalpy changes on the reboiler side, and extent of this change determines the approximate feed heating duty required.

- If a feed is excessively over heated, the stage- $H$ plots show a sharp enthalpy changes on the condenser side, and extent of this change determines the approximate feed cooling duty required.

- Changes in the heat duty of pre-heaters or pre-coolers lead to similar duty changes in the column reboiler or condenser loads, respectively [1]. 
Table 3 Sustainability metrics for column 1 with the modification: $N=50 \rightarrow 55$; $N F 1=25, N F 2=15$,

$N F 3=11$

$R R=0.65 \rightarrow 0.328$

TF1 $=-37{ }^{\circ} \mathrm{C} \rightarrow-30{ }^{\circ} \mathrm{C}$

\begin{tabular}{|c|c|c|c|}
\hline & \multicolumn{3}{|l|}{ Column 1} \\
\hline & Base case & Modified case & Change $(\%)$ \\
\hline \multicolumn{4}{|l|}{ Material intensity } \\
\hline Feed 1 rate $(\mathrm{kg} / \mathrm{s})$ & 27.03 & 27.03 & 0 \\
\hline Feed 2 rate $(\mathrm{kg} / \mathrm{s})$ & 16.62 & 16.62 & 0 \\
\hline Feed 3 rate $(\mathrm{kg} / \mathrm{s})$ & 1.04 & 1.04 & 0 \\
\hline Distillate rate $(\mathrm{kg} / \mathrm{s})$ & 0.83 & 0.83 & 0 \\
\hline Bottoms rate $(\mathrm{kg} / \mathrm{s})$ & 43.85 & 43.85 & 0 \\
\hline \multicolumn{4}{|l|}{ Energy intensity metrics } \\
\hline Condenser duty, $\mathrm{kJ} / \mathrm{s} /(\mathrm{kg} / \mathrm{s}$ distillate $), \mathrm{kJ} / \mathrm{kg}$ & -356.92 & -345.67 & -3.17 \\
\hline Reboiler duty, $\mathrm{kJ} / \mathrm{s} /(\mathrm{kg} / \mathrm{s}$ bottoms $), \mathrm{kJ} / \mathrm{kg}$ & 212.71 & 199.99 & -5.98 \\
\hline Feed conditioning, $\mathrm{kJ} / \mathrm{s} /(\mathrm{kg} / \mathrm{s}$ feed 1$), \mathrm{kJ} / \mathrm{kg}$ & 0 & 20.28 & - \\
\hline Condenser duty cost, $\$ / \mathrm{s} /(\mathrm{kg} / \mathrm{s}$ distillate $), \$ / \mathrm{kg}$ & 0.015 & 0.014 & -3.12 \\
\hline Reboiler duty cost, $\$ / \mathrm{s} /(\mathrm{kg} / \mathrm{s}$ bottoms $), \$ / \mathrm{kg}$ & 0.0007 & 0.0006 & -5.97 \\
\hline Duty in feed 1 conditioning cost, $\mathrm{kJ} / \mathrm{s} /(\mathrm{kg} / \mathrm{s}$ feed 1$), \$ / \mathrm{kg}$ & 0 & 0.00004 & - \\
\hline Total exergy loss, $\mathrm{kJ} / \mathrm{s} /(\mathrm{kg} / \mathrm{s}$ ethylene), $\mathrm{kJ} / \mathrm{kg}$ & 70.98 & 5.56 & -92.15 \\
\hline \multicolumn{4}{|l|}{ Environmental impact metrics } \\
\hline Condenser $\mathrm{CO}_{2}$ emission, $\mathrm{kg} / \mathrm{s} /(\mathrm{kg} / \mathrm{s} \text { distillate })^{\mathrm{a}}$ & 0.0198 & 0.0191 & -3.53 \\
\hline Reboiler $\mathrm{CO}_{2}$ emission, $\mathrm{kg} / \mathrm{s} /(\mathrm{kg} / \mathrm{s} \text { bottoms })^{\mathrm{a}}$ & 0.012 & 0.011 & -8.33 \\
\hline Feed conditioning $\mathrm{CO}_{2}$ emission, $\mathrm{kg} / \mathrm{s} /(\mathrm{kg} / \mathrm{s} \text { feed } 1)^{\mathrm{a}}$ & 0 & 0.001 & - \\
\hline
\end{tabular}

${ }^{a}$ Emission based on US-EPA-Rule-E9-5711 and natural gas
Because of the large differences of the temperature in the distillate and bottom flows, feed conditioning does not give satisfactory retrofits for columns. Heating the feed reduces the heat duty and the $\mathrm{CO}_{2}$ emission of the reboiler, but it increases them in the condenser. However, the feed conditioning represents better retrofits if applied with reflux ratio modification because reflux ratio modification decreases the duties and $\mathrm{CO}_{2}$ emission in both sides. Detailed results will be presented and discussed in "Reflux ratio modification" section.

\section{Reflux ratio modification}

The gap between the pinch point and ordinate suggests that the duties in the reboiler and condenser can be further reduced by reducing reflux ratio [1]. However, to maintain the separation, the number of stages must increase. NQ curves analysis can be applied to find the optimum number of stages and the optimum feed stage based on an objective function, which may minimize total hot and cold duties or reflux ratio. The NQ curves are applied on columns with an objective function of minimizing the total duty (reboiler + condenser). To generate NQ curves, several steps should be considered: (1) specify the total number of stages, (2) activate design specifications such as purity, recovery, and/or stage temperature, (3) specify upper and lower limits for the number of stages, (4) select feed stage for the feed tray optimization, and (5) specify the objective function.

\section{Side condensing or reboiling modification}

Side condensing or side reboiling is external modification at a convenient temperature level. The area between the ideal and actual enthalpy (the CGCC pinch point) can be used to determine the scope for side condensing or side reboiling. This area could be reduced by integrating side condensing or reboiling, (or both in some cases) on an appropriate stage $[1,10,18,23]$.

- If a significant area exists above the pinch, a side reboiler can be placed at a convenient temperature level. This allows heat supply to the column using a low-cost hot utility, thus lowering the overall operating costs.

- If a significant area exists below the pinch, a side condenser can be placed at a convenient temperature level. This allows heat removal from the column more effectively and by a cheaper cold utility, thus lowering the overall operating costs.

In the next section, the determination of scope of retrofits and possible modifications are discussed for each column. 
Fig. 5 Column 2 base case operation with $N=50$; $N F=28 ; R R=0.53 ; N$, number of total stages; $N F 1$, $N F 2$, and $N F 3$ are the feed stages, and $R R$ is the reflux ratio. a CGCC (stage- $H$ ), b exergy loss profile, and c hydraulic analysis (a)

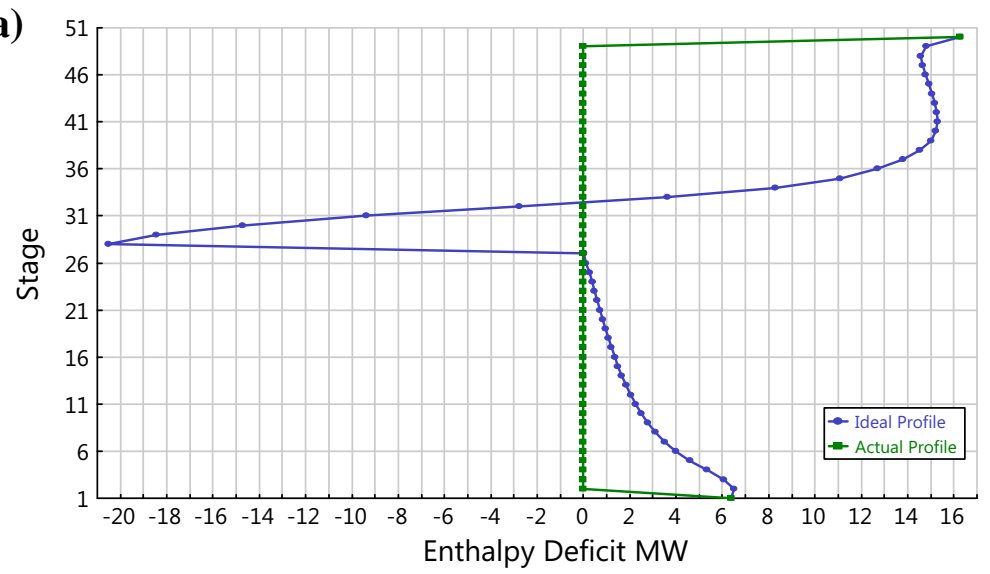

(b)

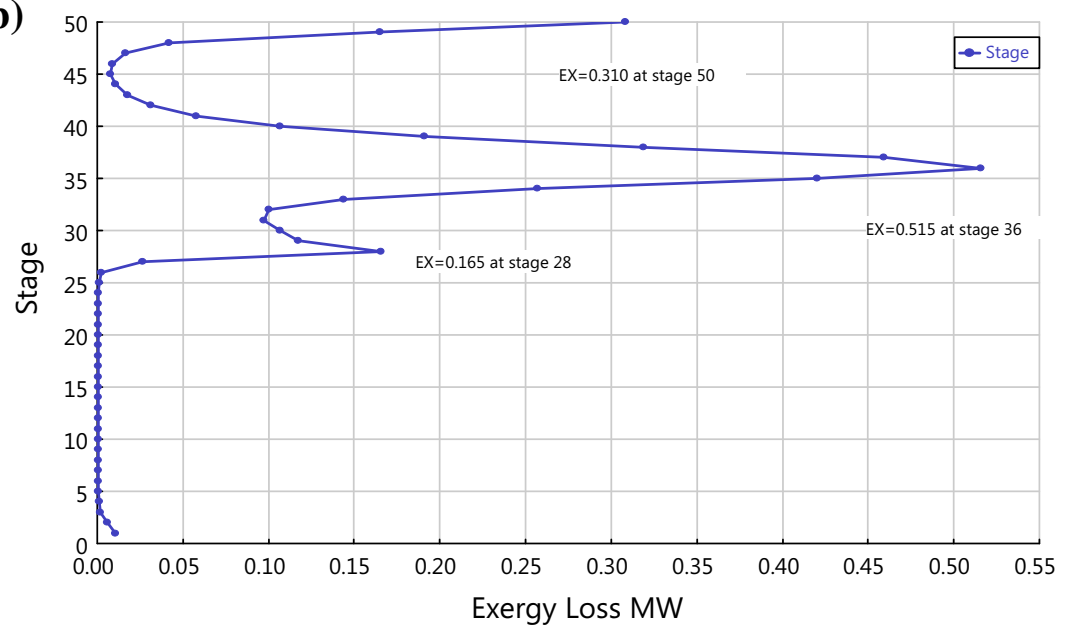

\section{Column 1}

Table 1 shows that the first column operates with three feed streams under cryogenic conditions. Figure 3 shows the stage- $H$ CGCC, exergy loss profiles, and hydraulic analysis for the base case operations
Stage- $H$ CGCC shown in Fig. 3a displays sharp changes for the feeds 2 and 3 on the condenser side, which require moving the feeds up the column toward condenser. Also, it displays sharp enthalpy change on the reboiler side, which requires heating the first feed. Therefore, the first feed has been heated to $-30{ }^{\circ} \mathrm{C}$ instead of $-37^{\circ} \mathrm{C}$. The small gap 
Fig. 6 Modified case operation for column 2 with $N=55$; $N F=33 ; R R=0.53 ; N$, number of total stages; $N F$ is the feed stage, and $R R$ is the reflux ratio. a CGCC (stage- $H$ ), and b exergy loss profiles
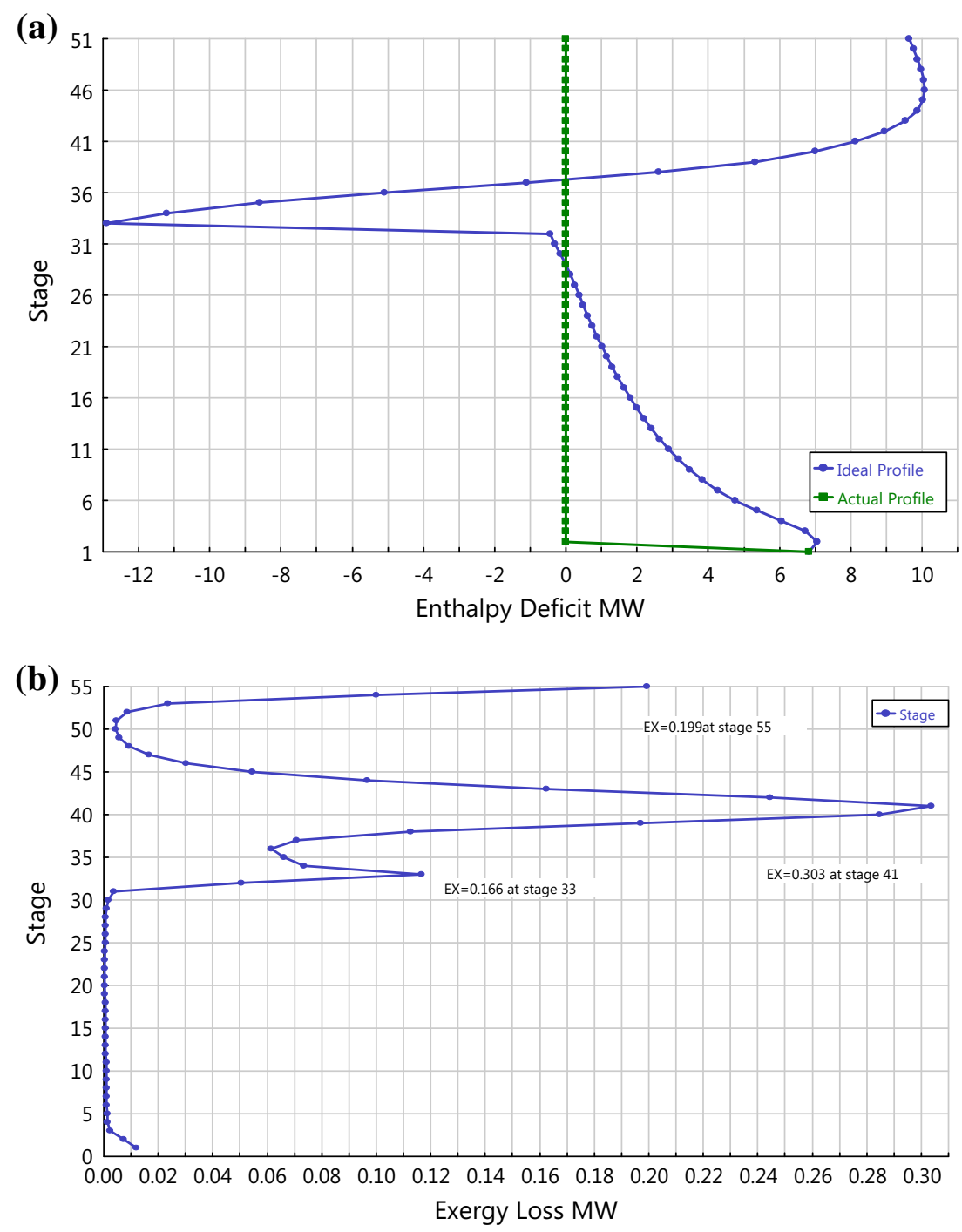

to the ordinate requires a reflux ratio modification which leads to changing in the number of stages. Therefore; NQ curve analysis is used to get 55 stages with reflux ratio of 0.38 , and the third feed is moved up the column for the $N F 3$ to be 11. Exergy loss profile shown in Fig. 3b displays the wasted available energy in the column and higher exergy losses on the feed stages, the reboiler, and the condenser. Figure $3 \mathrm{c}$ displays the vapor flow rate profile, which is near minimum in the feed stages and the reboiler and near maximum in the condenser. The supporting data show some of the data obtained from the NQ curve analysis.

NQ curves are applied for column 1 with $N=55$; $N F 1=25, N F 2=15, N F 3=11$, and $R R=0.32$, where $N$ is the number of total stages, NF1, NF2, and NF3 are the feed stages, and $R R$ is the reflux ratio. The results of NQ curve are presented in Table S5 within the supplementary data. Figure 4a displays the modified CGCC (stage- $H$ ) with relatively less heat deficits around the feed stages. Figure $4 \mathrm{~b}$ shows the exergy loss profiles of the column after the modifications. The total metrics of exergy losses on the feed stages are reduced from the base case of operation value of $70.98-5.57 \mathrm{~kW}$ per $\mathrm{kg} / \mathrm{s}$ ethylene after the modifications. Therefore, the total reduction is around $92 \%$. The hydraulic analysis shows that the changes in the internal vapor flow rates are negligible.

Table S5 in supplementary data compares the sustainability indicators, while Table 3 compares the sustainability metrics, which are normalized values with respect to unit mass of products for both the base case and modified case operations. The modifications applied are the reflux ratio, feed plate location, and heating feed 1 of column 1 . As seen, the modification have resulted in modest reductions in the duties, the cost of energy, and emissions of $\mathrm{CO}_{2}$, while reducing the exergy losses considerably. The emission calculations are based on $\mathrm{CO}_{2}$ emission factor 
Table 4 Sustainability metrics for column 2 with the modifications: $N=50 \rightarrow 55$; $N F=33 ; R R=0.65 \rightarrow 0.53$; $T F=5{ }^{\circ} \mathrm{C} \rightarrow 9{ }^{\circ} \mathrm{C}$

\begin{tabular}{|c|c|c|c|}
\hline & \multicolumn{3}{|l|}{ Column 2} \\
\hline & Base case & Modified case & Change $(\%)$ \\
\hline \multicolumn{4}{|l|}{ Material intensity } \\
\hline Feed rate $(\mathrm{kg} / \mathrm{s})$ & 43.85 & 43.85 & 0 \\
\hline Distillate rate $(\mathrm{kg} / \mathrm{s})$ & 38.12 & 38.12 & 0 \\
\hline Bottoms rate $(\mathrm{kg} / \mathrm{s})$ & 5.73 & 5.73 & 0 \\
\hline \multicolumn{4}{|l|}{ Energy intensity metrics } \\
\hline Condenser duty, $\mathrm{kJ} / \mathrm{s} /(\mathrm{kg} / \mathrm{s}$ distillate $), \mathrm{kJ} / \mathrm{kg}$ & -167.49 & -179.41 & +6.63 \\
\hline Reboiler duty, $\mathrm{kJ} / \mathrm{s} /(\mathrm{kg} / \mathrm{s}$ bottoms $), \mathrm{kJ} / \mathrm{kg}$ & 2837.58 & 1941.14 & -31.60 \\
\hline Feed conditioning, $\mathrm{kJ} / \mathrm{s} /(\mathrm{kg} / \mathrm{s}$ feed $), \mathrm{kJ} / \mathrm{kg}$ & 0 & 127.51 & - \\
\hline Condenser duty cost, $\$ / \mathrm{s} /(\mathrm{kg} / \mathrm{s}$ of distillate), $\$ / \mathrm{kg}$ & 0.0019 & 0.0021 & +6.63 \\
\hline Reboiler duty cost, $\$ / \mathrm{s} /(\mathrm{kg} / \mathrm{s}$ bottoms $), \$ / \mathrm{kg}$ & 0.0054 & 0.0038 & -31.60 \\
\hline Duty in feed conditioning cost, $\mathrm{kJ} / \mathrm{s} /(\mathrm{kg} / \mathrm{s}$ feed $), \$ / \mathrm{kg}$ & 0 & 0.0002 & - \\
\hline Total exergy loss, $\mathrm{kJ} / \mathrm{s} /(\mathrm{kg} / \mathrm{s}$ ethylene $), \mathrm{kJ} / \mathrm{kg}$ & 166.86 & 104.94 & -37.10 \\
\hline \multicolumn{4}{|l|}{ Environmental impact metrics } \\
\hline Condenser $\mathrm{CO}_{2}$ emission, $\mathrm{kg} / \mathrm{s} /(\mathrm{kg} / \mathrm{s} \text { distillate })^{\mathrm{a}}$ & 0.009 & 0.01 & +10.00 \\
\hline Reboiler $\mathrm{CO}_{2}$ emission, $\mathrm{kg} / \mathrm{s} /(\mathrm{kg} / \mathrm{s} \text { bottoms })^{\mathrm{a}}$ & 0.16 & 0.11 & -31.25 \\
\hline Feed conditioning $\mathrm{CO}_{2}$ emission, $\mathrm{kg} / \mathrm{s} /(\mathrm{kg} / \mathrm{s} \text { feed })^{\mathrm{a}}$ & 0 & 0.007 & - \\
\hline
\end{tabular}

${ }^{a}$ Emission based on US-EPA-Rule-E9-5711 and natural gas data source of US-EPA-Rule-E9-5711 and natural gas as the fuel source. Besides, the exergy loss is reduced by around $92 \%$ after the modifications leading to efficiently usage of available energy and more thermodynamically optimum operation.

Reflux ratio and number of stages modifications have no impact on the bottoms flow rate and compositions of column 1. This means that there is no impact on column 2 after column 1 reflux ratio and number of stages modifications.

\section{Column 2}

For the base case operation of column 2, which is summarized in Table 1, Fig. 5 shows CGCC (stage- $H$ ), exergy loss profiles, and hydraulic analysis. Figure 5a displays a sharp enthalpy change close to the reboiler side, which means that the feed heating may improve the operation. Also, reflux ratio modification may be required to further reduce the small gap to the ordinate. Figure $5 \mathrm{~b}$ shows that the exergy loss is higher in the feed stage, stage 36, and stage 55 . As Fig. $5 \mathrm{c}$ shows that the vapor flow rate is near minimum on the feed stage.

Using the NQ curves approach, which is available in supplementary data in Table S6; column 2 has been modified with $N=55 ; N F=33 ; R R=0.53$, where $N$ is the number of total stages, $N F$ is the feed stages, and the $R R$ is the reflux ratio. Figure 6a shows that the deficit at the feed stage has been reduced considerably on the CGCC (stage$H$ ) after changing the number of stages and heating the feed up to $9{ }^{\circ} \mathrm{C}$. Figure $6 \mathrm{~b}$ shows considerable reduction of around $37 \%$ in the exergy losses with the modified operations. The hydraulic analysis the vapor flow rate profiles are negligible after the modification.

Table S3, available in supplementary data, compares the sustainability indicators before and after modifications. Table 4 compares the sustainability metrics for the base case and modified case operations for column 2. As seen, the duties and cost of energy are decreased in the reboiler side, while the condenser duty is increased due to heating the feed. In a similar trend, the emissions of $\mathrm{CO}_{2}$ decreased around $31.6 \%$ in the reboiler, while increased around $6.6 \%$ in the condenser. This indicates the tradeoff taking place during the modifications. The reduced exergy losses lead to a more thermodynamically optimum operation.

\section{Column 3}

Column 3 uses the distillate rate of column 2 as the feed. Table 4 shows that distillate rate of column 2 remains the same after the modifications; therefore, column 3 base case does not change after the modifications on column 2. For the base case operation of column 3, Fig. 7 shows the stage- $H$ CGCC, exergy loss profiles, and hydraulic analysis. Figure 7a shows that the gap between the ordinate and the composite curve should to be reduced by modifying the reflux ratio. Figure $7 \mathrm{~b}$ displays large exergy losses on stages 23 and 41. The vapor flow rate (shown in Fig. 8c) reaches hydraulic maximum flow in stage 61 .

Using the NQ curve approach (see Table S7 in supplementary data), column 3 has been modified with $N=66$; $N F=35 ;$ and $R R=4.49$. Figure 8 shows the CGCC 
Fig. 7 Column 3 base case operation with $N=60$; $N F=35 ; R R=4.75 ; N$, number of total stages; $N F$ is the feed stages, and $R R$ is the reflux ratio. a CGCC (stage- $H$ ),

b exergy loss profile, and

c hydraulic analysis (a)

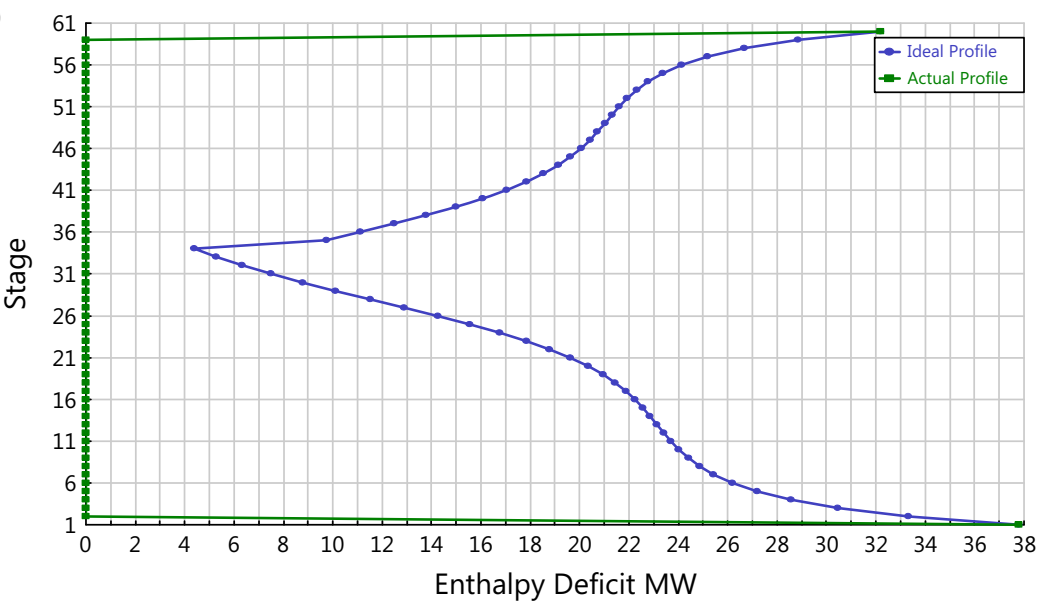

(b)
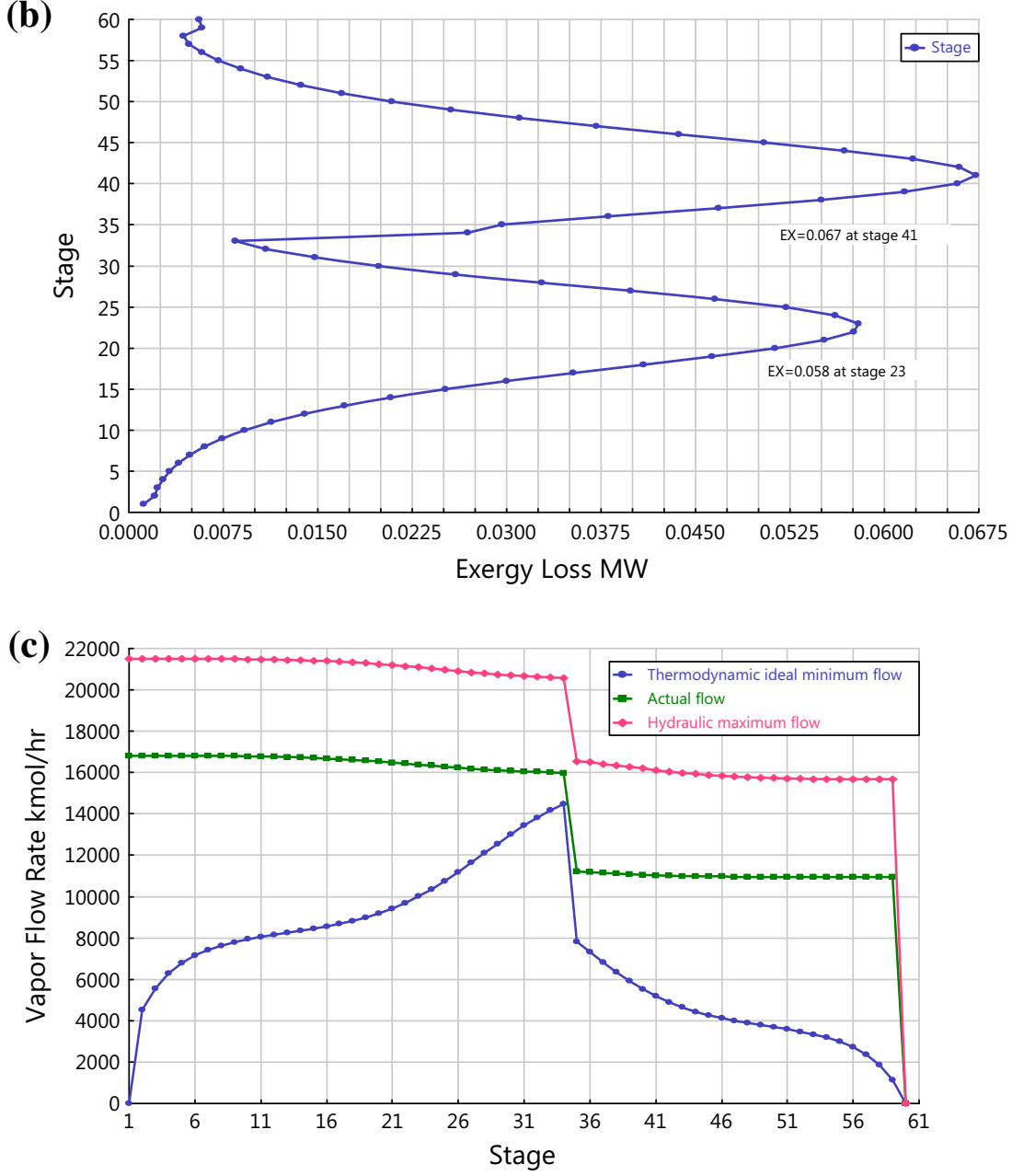

(stage- $H$ ) and exergy profiles after these modifications. The change in hydraulic analysis is negligible. Tables S4 and S5 in supplementary data compare the sustainability indicators and metrics, respectively, for the base case and modified case operations. The reduction in energy usage, energy cost, and exergy losses are achieved after the modifications. The sustainability metrics, shown in Table 5, indicate that the total exergy losses and total $\mathrm{CO}_{2}$ emissions are reduced around 17.4 and $20 \%$, respectively.

The side reboiling or condensing is the modification which is not applied in this study because it does not show the desired results. 
Fig. 8 Modified case operation for column 3 with $N=66$; $N F=35 ; R R=4.49 ; N$, number of total stages; $N F$ is the feed stage, and $R R$ is the reflux ratio. a CGCC (stage- $H$ ), and b exergy loss profiles
Table 5 Sustainability metrics for column 3 with modifications: $N=66$; $N F=35 ; R R=4.49$
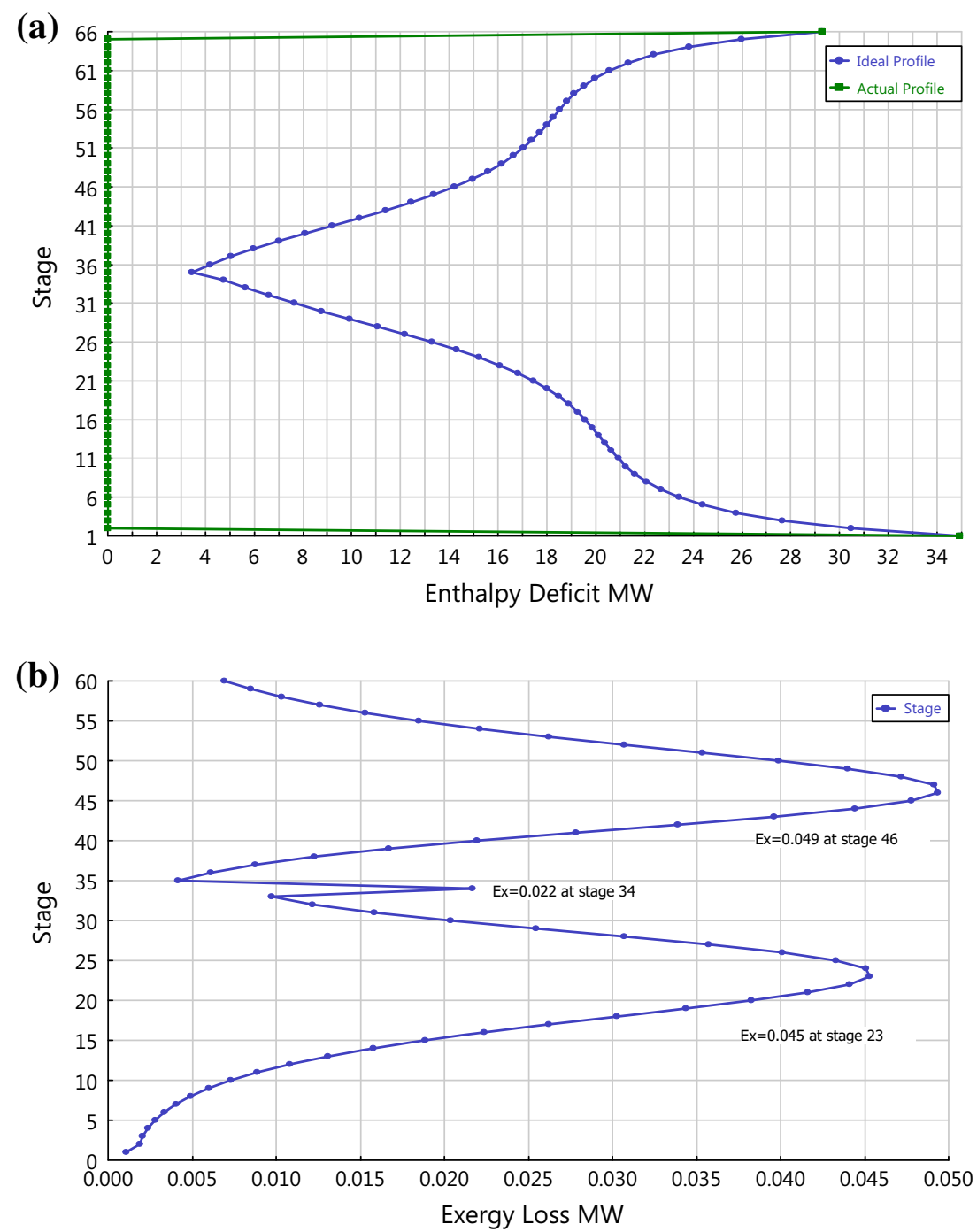

\begin{tabular}{|c|c|c|c|}
\hline & \multicolumn{3}{|l|}{ Column 3} \\
\hline & Base case & Modified case & Change (\%) \\
\hline \multicolumn{4}{|l|}{ Material intensity } \\
\hline Feed rate $(\mathrm{kg} / \mathrm{s})$ & 38.12 & 38.12 & 0 \\
\hline Distillate rate $(\mathrm{kg} / \mathrm{s})$ & 22.33 & 22.33 & 0 \\
\hline Bottoms rate $(\mathrm{kg} / \mathrm{s})$ & 15.78 & 15.78 & 0 \\
\hline \multicolumn{4}{|l|}{ Energy intensity metrics } \\
\hline Condenser duty, $\mathrm{kJ} / \mathrm{s} /(\mathrm{kg} / \mathrm{s}$ distillate), $\mathrm{kJ} / \mathrm{kg}$ & -1692.98 & -1570.57 & -7.23 \\
\hline Reboiler duty, $\mathrm{kJ} / \mathrm{s} / \mathrm{kg} / \mathrm{s}$ of bottoms), $\mathrm{kJ} / \mathrm{kg}$ & 2039.87 & 1845.17 & -9.54 \\
\hline Condenser duty cost, $\$ / \mathrm{s} /(\mathrm{kg} / \mathrm{s}$ of distillate), $\$ / \mathrm{kg}$ & 0.0286 & 0.0266 & -7.22 \\
\hline Reboiler duty cost, $\$ / \mathrm{s} /(\mathrm{kg} / \mathrm{s}$ of bottoms), $\$ / \mathrm{kg}$ & 0.0065 & 0.0058 & -9.58 \\
\hline Total exergy loss, $\mathrm{kJ} / \mathrm{s} /(\mathrm{kg} / \mathrm{s}$ ethylene), $\mathrm{kJ} / \mathrm{kg}$ & 75.29 & 62.18 & -17.40 \\
\hline \multicolumn{4}{|l|}{ Environmental impact metrics } \\
\hline Condenser $\mathrm{CO}_{2}$ emission, $\mathrm{kg} / \mathrm{s} /(\mathrm{kg} / \mathrm{s} \text { distillate })^{a}$ & 0.09 & 0.08 & -11.11 \\
\hline Reboiler $\mathrm{CO}_{2}$ emission, $\mathrm{kg} / \mathrm{s} /(\mathrm{kg} / \mathrm{s} \text { bottoms })^{\mathrm{a}}$ & 0.11 & 0.10 & -9.09 \\
\hline
\end{tabular}

${ }^{a}$ Emission based on US-EPA-Rule-E9-5711, natural gas 
Table 6 Estimated efficiencies and energy savings for the three columns

\begin{tabular}{|c|c|c|c|c|c|c|c|c|c|c|}
\hline \multirow[t]{2}{*}{ System } & \multicolumn{3}{|c|}{ Base case } & \multicolumn{7}{|c|}{ Modified case } \\
\hline & $\begin{array}{l}\mathrm{Ex}_{\min } \\
(\mathrm{MW})\end{array}$ & $\begin{array}{l}\text { Ex }_{\text {loss }} \\
(\mathrm{MW})\end{array}$ & $\eta(\%)$ & $\begin{array}{l}\mathrm{Ex}_{\min } \\
(\mathrm{MW})\end{array}$ & $\begin{array}{l}\text { Ex }_{\text {loss }} \\
(\mathrm{MW})\end{array}$ & $\eta(\%)$ & $\begin{array}{l}\text { Saved Ex } x_{\text {loss }} \\
\text { (MW) }\end{array}$ & $\begin{array}{l}\text { Change } \\
\text { Ex }_{\text {loss }}(\%)\end{array}$ & $\begin{array}{l}\text { FCC of } \\
\text { retrofits } \$^{\mathrm{a}}\end{array}$ & $\begin{array}{l}\text { Electricity } \\
\text { saving }(\$ / \text { year })^{b}\end{array}$ \\
\hline Column 1 & -2.63 & 1.58 & 62.4 & -2.48 & 0.12 & 95.2 & 1.46 & 92.2 & 100,600 & 964,038 \\
\hline Column 2 & -1.72 & 3.73 & 31.5 & -1.69 & 2.34 & 41.9 & 1.38 & 37.1 & 186,000 & 911,214 \\
\hline Column 3 & 0.77 & 1.68 & 31.4 & 0.97 & 1.39 & 41.0 & 0.29 & 17.1 & 338,000 & 191,487 \\
\hline Total & & 6.99 & & & 3.85 & & 3.14 & & 624,600 & $2,066,739$ \\
\hline
\end{tabular}

Ex $_{\text {loss }}$ : total column exergy loss from the converged simulation by Aspen Plus with the SRK method

${ }^{a}$ FCC fixed capital cost

${ }^{b}$ Electricity equivalent of energy saving is based on a unit cost of electricity of $\$ 0.0775 / \mathrm{kW}-\mathrm{h}$

Table 7 Estimated total reductions in hot and cold duties for the three columns

\begin{tabular}{lllllll}
\hline System & \multicolumn{2}{l}{ Base case } & & \multicolumn{2}{l}{ Modified case } \\
\cline { 2 - 3 } & Condenser (MW) & Reboiler (MW) & & Condenser (MW) & Reboiler (MW) & Feed conditioning (MW) \\
\hline Column 1 & -0.29 & 9.32 & 16.26 & -0.28 & 8.769 & 0.54 \\
Column 2 & -6.38 & 32.19 & & -6.83 & 11.123 & 5.59 \\
Column 3 & -37.81 & 57.78 & -35.08 & 29.125 & - \\
Total & -44.49 & & -42.20 & 49.018 & 6.13 \\
\hline
\end{tabular}

Table 8 Estimated total reductions in $\mathrm{CO}_{2}$ emissions for the three columns

\begin{tabular}{lll}
\hline System & $\begin{array}{l}\text { Base case } \\
\mathrm{CO}_{2} \text { emissions }(\mathrm{kg} / \mathrm{s})\end{array}$ & $\begin{array}{l}\text { Modified case } \\
\mathrm{CO}_{2} \text { emissions }(\mathrm{kg} / \mathrm{s})\end{array}$ \\
\hline Column 1 & 0.538 & 0.506 \\
Column 2 & 1.265 & 1.004 \\
Column 3 & 3.913 & 3.588 \\
Total & 5.716 & 5.098 \\
\hline
\end{tabular}

Table 6 shows the estimated thermodynamic efficiency and the energy savings based on electricity, which is around \$2 million against the fixed capital cost of around $\$ 624,600$ (2014 U.S. \$). This considerable energy saving, especially from reduction in exergy losses, also leads to the considerable $\mathrm{CO}_{2}$ reductions as shown in Tables 7 and 8; the total reductions in the cold utility is around is $5.1 \%$, while the total reductions in the hot utility is around $4.5 \%$.
Table 8 shows that the total reductions in the emission of $\mathrm{CO}_{2}$ are around $19.0 \%$. Table 9 shows the approximate total capital costs of $\$ 666,800$ for the retrofits against the total energy savings in electricity of around $\$ 2,066,739$. The hot utility for the feed conditioning of columns 1 and 2 has been counted in Table 9 .

\section{Conclusions}

As distillation columns are highly energy-intensive processes, tools for reducing the energy consumptions, and hence the carbon emissions through reasonable retrofits are highly valuable for petrochemical industry. One such tool, based on the thermodynamic analysis, is the column targeting tool (CTT) with capabilities of thermal and hydraulic analyses. By using the CTT, it is possible to assess the operations with the current configurations and
Table 9 Approximate total costs of the retrofits and duty

\begin{tabular}{lccclcc}
\hline Retrofits & Type & Duty $(\mathrm{kW})$ & $P($ bar $)$ & Material & Area $\left(\mathrm{m}^{2}\right)$ & Total cost $(\$)$ \\
\hline Col. 1 heater & S/T fixed $^{\mathrm{a}}$ & 550.0 & 36.88 & Carbon steel & 4.40 & 9900 \\
Col. 1 retrofit & & & & & & 110,500 \\
Col. 2 heater & S/T fixed & & \\
Col. 2 retrofit & 5590.0 & 34.47 & Carbon steel & 60.17 & 11,200 \\
Col. 3 retrofit & & & & & & 197,200 \\
Total & & & & & 338,000 \\
\hline
\end{tabular}

${ }^{a}$ S/T: fixed shell and tube 
determine the possible scope for improvements in modified configurations by suitable retrofits. Best possible column retrofits may be obtained by using the modifications on feed conditioning, feed stage, and reflux ratio. This analysis also includes the carbon tracking using an appropriate standard and a primary fuel. Using thermodynamic analysis, higher thermodynamic efficiencies are obtained for all the three columns, and the energy savings due to these modifications are about \$2 millions/year (2014 U.S. \$) after a one-time fixed capital cost of $\$ 664,000$. The reduction in total hot and cold utilities is around $10 \%$. Besides, the reduction in carbon emission is around $14 \%$. The results illustrate that it may be possible to achieve an improved and more sustainable distillation operation by simple retrofits determined by thermodynamic analysis.

Acknowledgments The authors would like thank the reviewers for their valuable comments and suggestions.

Authors' contributions Both authors, MA and YD, contributed equally in writing the paper. Both authors read and approved the final manuscript.

\section{Compliance with ethical standards}

Conflict of interest The authors declare that they have no competing interests.

Open Access This article is distributed under the terms of the Creative Commons Attribution 4.0 International License (http://crea tivecommons.org/licenses/by/4.0/), which permits unrestricted use, distribution, and reproduction in any medium, provided you give appropriate credit to the original author(s) and the source, provide a link to the Creative Commons license, and indicate if changes were made.

\section{References}

1. Demirel, Y.: Sustainable operations for distillation columns. Chem. Eng. Process. Tech. 1, 1005 (2013)

2. White, D.C.: Optimize energy use in distillation. Chem. Eng. Prog. 108, 35-41 (2012)

3. True, W.R.: Oil Gas J. 110, (2012). http://www.ogj.com/articles/ print/vol-110/issue-07/special-report-ethylene-report/global-ethy lene-capacity.html

4. Tahouni, N., Bagheri, J., Towfighi, M., Panjeshahi, H.: Improving energy efficiency of an olefin plant-a new approach. Energy Convers. Manag. 76, 453-462 (2013)
5. Pinto, F.S., Zemp, R., Jobson, M., Smith, R.: Thermodynamic optimization of distillation columns. Chem. Eng. Sci. 66, 2920-2934 (2011)

6. Demirel, Y.: Nonequilibrium Thermodynamics. Transport and Rate Processes in Physical, Chemical and Biological Systems, 3rd edn. Elsevier, Amsterdam (2014)

7. Bandyopadhyay, S., Malik, R.K., Shenoy, U.V.: Temperatureenthalpy curve for energy targeting of distillation columns. Comput. Chem. Eng. 22, 1733-1744 (1998)

8. Aspen Technology: http://www.aspentech.com/products/aspenplus.aspx. Accessed in 2013

9. Demirel, Y.: Thermodynamic analysis of separation systems. Sep. Sci. Technol. 39, 3897-3942 (2004)

10. Demirel, Y.: Exergy analysis of distillation columns. Int. J. Exergy 3, 345-361 (2006)

11. Demirel, Y.: Retrofit of distillation columns by thermodynamic analysis. Sep. Sci. Technol. 41, 791-817 (2006)

12. Martins, A.A., Mata, T.M., Costa, C.A.V., Sikdar, S.K.: Framework for sustainability metrics. Ind. Eng. Chem. Res. 46, 2962-2973 (2007)

13. Schwarz, J., Beloff, B.R., Beaver, E.: Use sustainability metrics to guide decision-making. CEP 98, 58-63 (2002)

14. Sikdar, S.K.: Sustainable development and sustainability metrics. AIChE J. 49, 1928-1932 (2003)

15. Tanzil, D., Beloff, B.R.: Overview on sustainability indicators and metrics. Environ. Qual. Manag. 15, 42-56 (2006)

16. Al-Muslim, H., Dincer, I.: Thermodynamic analysis of crude oil distillation systems. Int. J. Energy Res. 29, 637-655 (2005)

17. Ameta, G., Rachuri, S., Fiorentini, X., Mani, M., Fenves, S.J., Lyons, K.W., Sriram, R.D.: Extending the notion of quality from physical metrology to information and sustainability. J. Intell. Manuf. (2009). doi:10.1007/s10845-009-0333-3

18. Clift, R.: Sustainable development and its implications for chemical engineering. Chem. Eng. Sci. 61, 4179-4187 (2006)

19. De Koeijer, G.M., Rivero, R.: Entropy production and exergy loss in experimental distillation columns. Chem. Eng. Sci. 58, 1587-1597 (2003)

20. Dhole, V.R., Linnhoff, B.: Distillation column targets. Comput. Chem. Eng. 17, 549-560 (1993)

21. Rivero, R., Garcia, M., Urquiza, J.: Simulation, exergy analysis and application of diabatic distillation to a tertiary amyl methyl ether production unit of a crude oil refinery. Energy 29, 467-489 (2004)

22. CWRT, Center For Waste Reduction, Technologies Focus Area: Sustainability metrics 2004. http://www.aiche.org/cwrt/pdf/Base lineMetrics.pdf. Accessed in 2013

23. ChemE. Sustainable development progress metrics recommended for use in the process industries, 2004. http://www.icheme.org/ sustainability/metrics.pdf. Accessed in 2013

24. Seider, W.D., Seader, J.D., Lewin, D.R., Widagdo, S.: Production and Process Design Principle, 3rd edn. Wiley, New York (2009) 